\title{
A study on haloperidol and risperidone induced metabolic derangements in patients with newly diagnosed schizophrenia
}

\author{
Kiruthika Sivagourounadin ${ }^{1 *}$, Vijayalakshmi Subbiah², Geetha Krishnasamy ${ }^{3}$, \\ Priyadharsini Rajendran ${ }^{1}$
}

\author{
${ }^{1}$ Department of Pharmacology, JIPMER, Puducherry, India \\ ${ }^{2}$ Department of Pharmacology, Karpaga Vinayagar Institute of Medical Sciences, Maduranthagam, Tamil Nadu, India \\ ${ }^{3}$ Department of Pharmacology, Sivagangai Medical College, Sivagangai, Tamil Nadu, India
}

Received: 29 November 2019

Accepted: 08 January 2020

*Correspondence:

Dr. Kiruthika Sivagourounadin,

Email: drkiruthikasivagourou@gmail.com

Copyright: (C) the author(s), publisher and licensee Medip Academy. This is an open-access article distributed under the terms of the Creative Commons Attribution Non-Commercial License, which permits unrestricted non-commercial use, distribution, and reproduction in any medium, provided the original work is properly cited.

\begin{abstract}
Background: The occurrence of metabolic abnormalities in schizophrenic patients has been increased with the rampant use of second-generation antipsychotics. The aim and objective of this study is to compare the metabolic derangements induced by a typical antipsychotic: haloperidol and an atypical antipsychotic, risperidone in patients with newly diagnosed schizophrenia in a tertiary care hospital.

Methods: Out of 60 newly diagnosed schizophrenic patients, 30 patients received tablet haloperidol and the remaining 30 patients received tablet risperidone orally. The anthropometric measurements like height, weight, waist circumference was measured and blood investigations like fasting blood glucose level and fasting lipid profile were taken at baseline and at the end of 3 and 6 months of drug therapy. The metabolic derangements induced by the two antipsychotics were compared and analyzed at end of 3rd and 6th month using SPSS software version 16.

Results: At the end of 6th month statistically significant differences $(p<0.05)$ were observed in weight, waist circumference, fasting blood sugar, fasting triglyceride and high-density lipoprotein level between the haloperidol and risperidone group on following the International Diabetic Federation (IDF) criteria of metabolic syndrome. Risperidone caused metabolic abnormalities in $13.3 \%, 4$ patients whereas none of the patients in haloperidol group developed metabolic syndrome.

Conclusions: Hence it is concluded that the atypical antipsychotic risperidone has been associated with an increased risk of causing metabolic abnormalities than the typical antipsychotic haloperidol. Regular and periodic monitoring of the anthropometric and metabolic parameters in schizophrenic patients on antipsychotics especially the atypical antipsychotics is mandatory to prevent further complications.
\end{abstract}

Keywords: Metabolic syndrome, Schizophrenia, Haloperidol, Risperidone, Atypical antipsychotic, Typical antipsychotic

\section{INTRODUCTION}

Schizophrenia is a common chronic psychotic disorder characterized by splitting of perception and interpretation from reality and inability to think coherently. According to the Global Burden of Diseases, following cardiovascular diseases, schizophrenia is the second major disabling disorder in the world. It is an early onset disease, affecting people in their most crucial part of life either in late adolescence or early adulthood and thereby it creates a major impact on their family and society. ${ }^{1}$ In schizophrenia, the central role of pharmacotherapy is played by the antipsychotic drugs which are very 
effective for reducing the impact of psychotic symptoms on the quality of life of patients. The choice of antipsychotic drugs depends on the patient symptomatology, behaviour and drug resistance. ${ }^{2}$

The antipsychotic drugs are classified into two groups such as typical or conventional or first-generation antipsychotics and second generation or atypical antipsychotics. But these drugs act as a double-edged sword, apart from controlling the symptoms, they also cause serious adverse effects which might be due to the extension of their pharmacological actions or by a different mechanism. The typical or first-generation antipsychotics have more propensity to cause extra pyramidal symptoms. On the other hand, the atypical or second-generation antipsychotics have lower risk of causing extra pyramidal symptoms and are more effective on negative symptoms and are also useful in refractory cases. Thus, they appear to have several advantages over the typical antipsychotics. Currently the atypical antipsychotics are most commonly prescribed not only for schizophrenia but also for other psychotic disorders like bipolar mood disorder. This rampant use of secondgeneration antipsychotics is also associated with a newer group of adverse effects like increased risk of developing metabolic syndrome and cardiovascular diseases. ${ }^{3}$

Several long-term prospective studies have been done in western countries as well as in India comparing the prevalence of metabolic syndrome between first generation antipsychotics (FGA) and second-generation antipsychotics (SGA). They have reported the firstgeneration antipsychotics to carry lower risk of causing metabolic abnormalities. But studies on the comparison of the prevalence of metabolic syndrome caused by the two groups of antipsychotics in schizophrenic patients among the South Indian population are scarce. In our government tertiary care hospital, haloperidol and risperidone were the most commonly used antipsychotics in the psychiatric department for treating schizophrenia. So, a comparative study was planned between the two groups of patients with newly diagnosed schizophrenia who were treated with either one of the candidate drugs namely haloperidol (typical) or risperidone (atypical) antipsychotic. The metabolic derangements were kept as the main parameter for the comparison of side effect profile of the two groups of antipsychotics.

\section{METHODS}

\section{Study centre and design}

It is a prospective observational study conducted from December 2014 to June 2016 in the outpatient department of psychiatry, after obtaining clearance from Institutional ethical committee at Government Rajaji Hospital, Madurai. Sixty newly diagnosed patients with schizophrenia, attending psychiatric outpatient department were selected based on the eligibility criteria.

\section{Study participants}

\section{Inclusion criteria}

Newly diagnosed male/female patients with Schizophrenia as per ICD-10 criteria, between 18 to 60 years were explained about the proposed study and subjects who were willing to give written informed consent were selected.

\section{Exclusion criteria}

Patients with history of prior treatment with antipsychotics, patients having obesity or any of the five features of metabolic syndrome at the first time of examination [according to International Diabetic Federation Criteria], patients with diabetes mellitus, hypertension, liver, renal, cardiac disease, epilepsy were excluded. Pregnant and lactating women, patients with tuberculosis, HIV/AIDS were also excluded.

The patient or legally acceptable representative (LAR) of the patient were personally explained in local language about the details of the study. Written informed consent was obtained from patient or LAR. Sixty patients satisfying the inclusion criteria were selected over a period of one year were included in this study. They were divided into two groups and group A received tablet haloperidol and group B received tablet risperidone. They were followed up for a total duration of 6 months and the parameters determining the presence of metabolic syndrome were obtained at start of the study, at 3 months and at the end of 6 months.

\section{Conduct of study}

At visit 0 (baseline) a full clinical examination was done and their anthropometric measurements (weight, height, waist circumference) and blood pressure were recorded. The baseline investigations like fasting blood glucose and fasting lipid profile were done. The waist circumference was measured at the highest point of the iliac crest at minimal respiration. Three blood pressure measurements at five-minute intervals were obtained with the participant in the seated position and mean of these measurements was recorded. Their body mass index (BMI) was calculated and was categorized according to WHO classification of BMI for adults. Weight, waist circumference, blood pressure and blood investigations like fasting blood glucose level, fasting lipid profile were repeated at the end of 3 months and 6 months of treatment with haloperidol or risperidone in their respective groups. International Diabetic Federation (2005) definition for metabolic syndrome (for South Asians including Indians) criteria was used to assess the development of metabolic syndrome which includes parameters such as (1) central obesity, waist circumference was $\geq 90 \mathrm{~cm}$ in South Asian men and $\geq 80$ $\mathrm{cm}$ in South Asian women, (2) hypertriglyceridemia was $\geq 150 \mathrm{mg} / \mathrm{dl}$, (3) low HDL cholesterol was $40 \mathrm{mg} / \mathrm{dl}$ in 
men and $<50 \mathrm{mg} / \mathrm{dl}$ in women, (4) high blood pressure was $\geq 130 / 85 \mathrm{mmHg}$ and (5) high fasting glucose was $\geq 100 \mathrm{mg} / \mathrm{dl}$

The patient was diagnosed to have metabolic syndrome if he/she had central obesity and other 2 or more features of the criteria

\section{Labeling of study medications}

The recruited patients were followed up once in fifteen days for the first two months (for refilling the prescription) and later once a month till the end the study. The strips of tablets were cut into single units and the required number of tablets for 15 days were placed in a cover and given to patients on visit 0 and they were asked to bring empty blister packs for pill counting. They were advised not to take any other medications without the knowledge of investigator. Study participants were advised to return the used blister packs at the next visit in order to maintain accountability of study medications.

\section{Statistical analysis}

The data were analysed with SPSS statistical software package (Version 16.0 SPSS Inc., Chicago, USA). The changes induced by the two antipsychotics in the anthropometric and metabolic parameters defining the presence of metabolic syndrome was compared using students $\mathrm{t}$ test and $\mathrm{p}<0.05$ will be considered as statistically significant.

\section{RESULTS}

Totally sixty patients were recruited for the study after satisfying the inclusion and exclusion criteria and they were divided into two groups A and B. Group A received tablet haloperidol and group $\mathrm{B}$ received tablet risperidone. They were followed up for a total duration of 6 months and the parameters determining the presence of metabolic syndrome were measured at start of the study, at 3 months and at the end of 6 months. There was no drop out in the study, all the sixty patients completed the six-month study and all of them were analysed.

Out of the sixty patients analysed, 33 were females and the rest were males. The haloperidol group had 14 males and 16 females, while the risperidone group had 13 males and 17 females. The mean age of the sixty patients included was $36.3 \pm 8.3$ years. The majority of patients (25) belonged to 31 to 40 years of age. Among the rest of them 20,18 and 13 patients were between 51 to 60,21 to 30 and 31 to 40 years of age respectively.

The mean values of weight, body mass index, waist circumference, fasting triglycerides, fasting high density lipoprotein and fasting blood sugar in haloperidol and risperidone group observed at baseline and at the end of 3 and 6 months are elucidated in Tables 1,2, 3 respectively.

Table 1: Comparison of anthropometric and metabolic parameters at baseline.

\begin{tabular}{|lllll|}
\hline S. no. & $\begin{array}{l}\text { Clinical } \\
\text { characteristics }\end{array}$ & $\begin{array}{l}\text { Haloperidol group } \\
\text { (Mean } \pm \text { SD) }\end{array}$ & $\begin{array}{l}\text { Risperidone group } \\
\text { (Mean } \pm \text { SD) }\end{array}$ & P value \\
\hline $\mathbf{1}$ & Weight $(\mathrm{kg})$ & $64.3 \pm 9.6$ & $65.9 \pm 8$ & 0.7 \\
\hline $\mathbf{2}$ & BMI & $23 \pm 1.8$ & $23.8 \pm 1.09$ & 0.2 \\
\hline $\mathbf{3}$ & Waist circumference $(\mathrm{cm})$ & $78.9 \pm 4.06$ & $79 \pm 4.9$ & 0.5 \\
\hline $\mathbf{4}$ & Fasting HDL (mg/dl) & $51.63 \pm 4.8$ & $50.96 \pm 4.6$ & 0.7 \\
\hline $\mathbf{5}$ & Fasting TG (mg/dl) & $124.93 \pm 11.4$ & $125.23 \pm 11.3$ & 0.9 \\
\hline $\mathbf{6}$ & Fasting Blood Sugar $(\mathrm{mg} / \mathrm{dl})$ & $77.26 \pm 7.11$ & $77.93 \pm 7.3$ & 0.7 \\
\hline $\mathbf{7}$ & Systolic Blood Pressure $(\mathrm{mmHg})$ & $115.33 \pm 6.28$ & $115.33 \pm 6.2$ & 1.0 \\
\hline $\mathbf{8}$ & Diastolic Blood Pressure $(\mathrm{mmHg})$ & $74.66 \pm 5.07$ & $74.66 \pm 5.07$ & 1.0 \\
\hline
\end{tabular}

HDL: High-density lipoprotein; TG: Triglycerides.

Table 2: Comparison of anthropometric and metabolic parameters at the end of 3 months.

\begin{tabular}{|lllll|}
\hline S. no. & $\begin{array}{l}\text { Clinical } \\
\text { characteristics }\end{array}$ & $\begin{array}{l}\text { Haloperidol group } \\
\text { Mean } \pm \text { SD) }\end{array}$ & $\begin{array}{l}\text { Risperidone group } \\
\text { (Mean } \pm \text { SD) }\end{array}$ & P value \\
\hline $\mathbf{1}$ & Weight $(\mathrm{kg})$ & $64.56 \pm 9.7$ & $67.9 \pm 9.2$ & 0.1 \\
\hline $\mathbf{2}$ & BMI & $23.08 \pm 1.8$ & $24.56 \pm 1.2$ & 0.1 \\
\hline $\mathbf{3}$ & Waist circumference $(\mathrm{cm})$ & $79 \pm 4.19$ & $82.06 \pm 5.5$ & $0.01^{*}$ \\
\hline $\mathbf{4}$ & Fasting HDL $(\mathrm{mg} / \mathrm{dl})$ & $51.33 \pm 4.2$ & $49.93 \pm 4.8$ & 0.2 \\
\hline $\mathbf{5}$ & Fasting TG $(\mathrm{mg} / \mathrm{dl})$ & $126.46 \pm 11.6$ & $129.13 \pm 13.7$ & 0.4 \\
\hline $\mathbf{6}$ & Fasting Blood Sugar $(\mathrm{mg} / \mathrm{dl})$ & $79.06 \pm 7.45$ & $82.93 \pm 11.7$ & 0.1 \\
\hline $\mathbf{7}$ & Systolic Blood Pressure $(\mathrm{mmHg})$ & $115.33 \pm 6.28$ & $115.33 \pm 6.2$ & 0.8 \\
\hline $\mathbf{8}$ & Diastolic Blood Pressure $(\mathrm{mmHg})$ & $74.66 \pm 5.07$ & $74.66 \pm 5.07$ & 1.0 \\
\hline
\end{tabular}

HDL: High-density lipoprotein; TG: Triglycerides. 
Table 3: Comparison of anthropometric and metabolic parameters at the end of 6 months.

\begin{tabular}{|lllll|}
\hline S. no. & $\begin{array}{l}\text { Clinical } \\
\text { characteristics }\end{array}$ & $\begin{array}{l}\text { Haloperidol group } \\
\text { (Mean } \pm \text { SD) }\end{array}$ & $\begin{array}{l}\text { Risperidone group } \\
(\text { Mean } \pm \text { SD) }\end{array}$ & P value \\
\hline $\mathbf{1}$ & Weight $(\mathrm{kg})$ & $65.1 \pm 9.7$ & $71.06 \pm 9.2$ & $0.02^{*}$ \\
\hline $\mathbf{2}$ & BMI & $23.3 \pm 1.8$ & $25.6 \pm 1.2$ & $0.00^{*}$ \\
\hline $\mathbf{3}$ & Waist circumference $(\mathrm{cm})$ & $79.3 \pm 4.54$ & $83.66 \pm 6.05$ & $0.003^{*}$ \\
\hline $\mathbf{4}$ & Fasting HDL (mg/dl) & $51.16 \pm 4.6$ & $48.06 \pm 7.9$ & $0.03^{*}$ \\
\hline $\mathbf{5}$ & Fasting TG (mg/dl) & $127.66 \pm 10.9$ & $135.8 \pm 18.4$ & $0.04^{*}$ \\
\hline $\mathbf{6}$ & Fasting Blood Sugar (mg/dl) & $79.36 \pm 7.60$ & $87.7 \pm 17.11$ & $0.01^{*}$ \\
\hline $\mathbf{7}$ & Systolic Blood Pressure $(\mathrm{mmHg})$ & $115.33 \pm 6.28$ & $116 \pm 6.7$ & 0.6 \\
\hline $\mathbf{8}$ & Diastolic Blood Pressure $(\mathrm{mmHg})$ & $74.66 \pm 5.07$ & $75.33 \pm 5.7$ & 0.6 \\
\hline
\end{tabular}

HDL: High-density lipoprotein; TG: Triglycerides. ${ }^{*} \mathrm{P}$ value $\leq 0.05$ is considered statistically significant.

Table 4: Total number of patients with metabolic syndrome at the end of 6 months $(n=30)$.

\begin{tabular}{|c|c|c|c|}
\hline \multirow[t]{2}{*}{ Patient group } & $\begin{array}{l}\text { Patients not having metabolic } \\
\text { syndrome }\end{array}$ & $\begin{array}{l}\text { Patients having metabolic } \\
\text { syndrome }\end{array}$ & \multirow[t]{2}{*}{ P value } \\
\hline & $\mathbf{N}(\%)$ & $\mathbf{N}(\%)$ & \\
\hline Haloperidol & $30(100)$ & 0 & \multirow{2}{*}{$0.03^{*}$} \\
\hline Risperidone & $26(86.7)$ & $4(13.3)$ & \\
\hline
\end{tabular}

$* \mathrm{P}$ value $\leq 0.05$ is considered statistically significant.

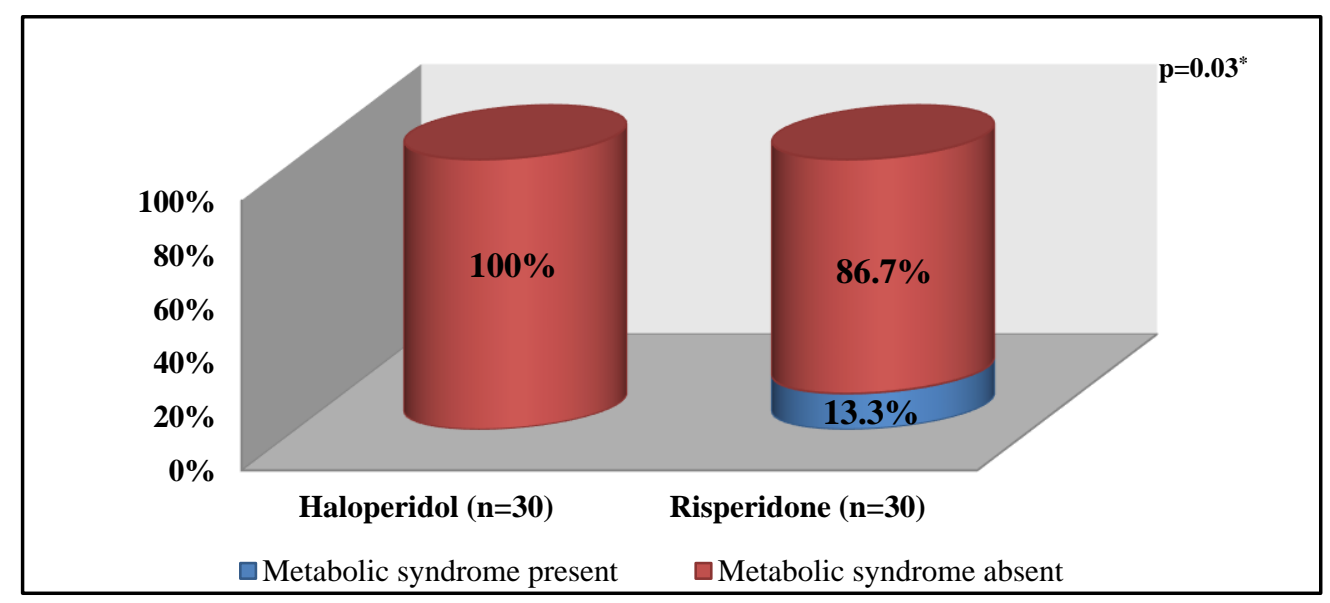

Figure 1: Total number of patients with metabolic syndrome at the end of 6 months.

*P value $\leq 0.05$ is considered statistically significant.

\section{At baseline}

Both in the haloperidol and risperidone group, all the patients were in the normal range according to WHO classification of adults based on BMI. The mean weight gain induced by haloperidol and risperidone was $0.87 \pm 0.8$ $\mathrm{kg}$ and $5.1 \pm 1.5 \mathrm{~kg}$ respectively at the end of 6 months.

In both the treatment groups the number of patients with changes in the anthropometric ad metabolic parameters were as follows

\section{At the end of three months}

In haloperidol group, increase in waist circumference was noted in one female and decrease in HDL level was observed in one female. In risperidone group, 11 patients (4 males and 7 females) showed increase in waist circumference and for 3 females there was decrease in HDL levels, increase in fasting triglycerides and fasting blood sugar.

\section{At the end of six months}

In haloperidol group, totally 2 patients $(1$ male and 1 female) showed increase in waist circumference and decrease in HDL level was observed in two females. In risperidone group, totally 13 patients (5 males and 8 females) showed increase in waist circumference and decrease in HDL level was observed in 7 patients (4 males and 3 females). Increase in fasting triglycerides and fasting blood sugar was observed in five patients ( 2 males and 3 females). In the whole group of 60 patients, increase in blood pressure of $>130 / 90 \mathrm{mmHg}$ was observed in only one female patient in risperidone group. 
The changes induced by the two antipsychotics in the anthropometric and metabolic parameters defining the presence of metabolic syndrome was compared using students $\mathrm{t}$ test.

At the end of three months on comparing the metabolic derangements induced by haloperidol and risperidone, there were statistically significant changes present only for one parameter namely waist circumference $(p<0.05)$ (Table 2). At the end of 6 months, statistically significant changes were observed in parameters like body weight, body mass index, waist circumference, fasting HDL, fasting triglyceride and fasting blood sugar levels $(\mathrm{p}<0.05)$ (Table 3). As shown in Table 4 and Figure 1, during the six months treatment with two different antipsychotics, totally 4 patients $(13.3 \%)$ ( 2 females at the end of three months and 2 males at the end of six months) developed metabolic syndrome in the risperidone group according to the International Diabetic Federation (IDF) criteria. Whereas in the haloperidol group, metabolic syndrome was not observed in any of the patients. This difference between two drug groups was compared using chi-square test and it was statistically significant $(\mathrm{p}<0.05)$.

\section{DISCUSSION}

Several cross-sectional and prospective studies done in the western countries have reported the prevalence of metabolic syndrome in antipsychotic treated schizophrenics to be in the range of $22-66 \% .^{4,5}$ Long term prospective studies done in western countries as well as in India comparing the prevalence of metabolic syndrome between FGA and SGA have reported the first generation antipsychotics to carry lower risk of causing metabolic abnormalities. ${ }^{6,7}$

In a total of sixty patients who participated in this study, $71.7 \%$ of patients were in the most productive phase of life that is $20-40$ years and $6.7 \%$ of them were more than 50 years of age.

Study by Cohn et al has highlighted the fact that the prevalence of metabolic syndrome among schizophrenics was more common in younger age group than the general population. $^{8}$ In our study also similar pattern of occurrence of metabolic syndrome was observed. $13.3 \%$ of the patients who developed metabolic syndrome at the end of 6 months were in the age group of 31-40 years.

In their studies McEvoy et al and De Hert et al have reported the females to be at an increased risk of developing metabolic syndrome in majority of the ethnic groups. ${ }^{9,10}$ But in our study the prevalence $(13.3 \%)$ of metabolic derangements were equally distributed in 2 female and 2 male patients. This absence of gender difference for the occurrence of metabolic abnormalities might be due to the small sample size.
In the present study, the mean weight gain induced by risperidone was $5.1 \pm 1.5 \mathrm{~kg}$ and it was significantly more than that induced by haloperidol $0.87 \pm 0.8 \mathrm{~kg}$ at the end of 6 months. Our finding was similar to the prospective study done by Gautam et al, where the weight gain observed was $4 \mathrm{~kg}$ in the risperidone group and $2.8 \mathrm{~kg}$ in the haloperidol group. Other study by Perez et al also have reported higher mean weight gain of $5.9 \mathrm{~kg}$ with risperidone than the mean weight gain of $3.8 \mathrm{~kg}$ seen in haloperidol group. ${ }^{11,12}$

The other anthropometric parameter which was observed by us was body mass index and it showed statistically significant $(\mathrm{p}<0.05)$ difference between the haloperidol and risperidone groups at the end of 6 months of drug therapy. These findings were similar to those observed by De Hert et al in their retrospective systematic review done to compare the incidence of metabolic syndrome induced by first generation antipsychotics and second-generation antipsychotics. ${ }^{10}$

In a 6-week double-blind, prospective study done by Saddicha et al increase in waist circumference according to the IDF criteria of metabolic syndrome was reported in $27.3 \%$ and $16.1 \%$ patients in risperidone and haloperidol group respectively. ${ }^{13}$ On following the IDF criteria of metabolic syndrome we observed increase in waist circumference in $21.6 \%$ patients in risperidone group and in $6.6 \%$ patients in haloperidol group at the end of 6 months.

In our study, it was noted that from baseline the fasting blood sugar levels showed an increase of $9.77 \mathrm{mg} / \mathrm{dl}$ and $2.1 \mathrm{mg} / \mathrm{dl}$ in the risperidone and haloperidol group respectively. Similar changes in fasting blood sugar values were found by Lindenmayer et al and Saddicha et al in their prospective studies on occurrence of glucose intolerance with antipsychotics. ${ }^{7,14}$

We observed statistically significant $(\mathrm{p}<0.01)$ differences in fasting plasma levels of triglycerides and high-density lipoprotein between the haloperidol and risperidone group at the end of six months. These findings are in accordance to the changes in the TG and HDL reported by Barnwal et al and Saddicha et al. ${ }^{13,15}$

Similar to the pattern reported by Grover et al, in our study also among the parameters evaluated for the presence of metabolic syndrome, increase in waist circumference was the most common abnormality observed. ${ }^{16}$ Unlike the changes observed in blood pressure by Saddicha et al, significant changes in SBP and DBP were not noted in both the drug treatment groups in our study. ${ }^{13}$

Out of the sixty patients included in the study about $13.3 \%$ patients in risperidone group developed metabolic syndrome, whereas none of the patients in the haloperidol group developed metabolic syndrome at the end of six 
months. Our findings were in common to those observed by Gautam et al, where in their study $10 \%$ of patients in risperidone group and none of the patients in haloperidol group developed metabolic syndrome. ${ }^{11}$ And similarly, Saddicha et al reported that the prevalence of metabolic syndrome was $9-24 \%$ in risperidone group and $0-3 \%$ in haloperidol group in their study. ${ }^{13}$ In their systematic review on antipsychotic drugs induced metabolic syndrome in schizophrenia Chadda et al concluded the second-generation antipsychotics like olanzapine, clozapine and risperidone have more propensity to cause metabolic syndrome than first generation antipsychotics like haloperidol. ${ }^{17}$

Small sample size and open labelled non-blinded techniques were the limitations of our study. Hence studies with larger sample size can be done to generalize the results of the study. Early identification and treatment of the metabolic abnormalities can bring down the morbidity and mortality associated with the coronary artery disease in schizophrenics, which is more prevalent among our population. Hence it is concluded that even though the second-generation antipsychotics offer certain advantages over the first-generation antipsychotics, they tend to carry a higher risk of causing metabolic abnormalities. Thus, regular and periodic monitoring of the anthropometric and metabolic parameters in schizophrenic patients on antipsychotics especially the atypical antipsychotics by the physicians may bring a change in the medical and social problems created by metabolic syndrome in schizophrenic patients.

Funding: No funding sources

Conflict of interest: None declared

Ethical approval: The study was approved by the Institutional Ethics Committee (13432/E1/5/2014)

\section{REFERENCES}

1. Lawrence RE, First MB, Lieberman JA. Schizophrenia and Other Psychoses. In: Tasman A, Kay J, Riba MB (eds). Psychiatry. 4th edition, London: John Wiley \& Sons; 2015: 791-798.

2. Schizophrenia JA. Course and Outcome. In: Gelder MG, Andreasen NC, Lopez-Ibor JL, Geddes JR (eds). New Oxford Textbook of Psychiatry. 2nd edition. New Delhi: Oxford University press; 2012: 568-572.

3. Standaert DG, Sung VM. Pharmacology of Dopaminergic Neurotransmission. In: Golan DE, Armstrong EJ, Armstrong AW, (eds). Principles of Pharmacology: The Pathophysiologic Basis of Drug Therapy, 4th edition. Philadelphia: Wolters Kluwer Health; 2017: 207-19.

4. Patel JK, Buckley PF, Woolson S, Hamer RM, McEvoy JP, Perkins DO, et al. Metabolic profiles of second-generation antipsychotics in early psychosis: Findings from the CAFE study. Schizophr Res. 2009;111:9-16.
5. Mainar AS, Tamayo MB, Gutierrez JR, Artieda RN. Metabolic syndrome in outpatients receiving antipsychotic therapy in routine clinical practice: a cross-sectional assessment of a primary health care database. Eur Psychiatry. 2008;23:100-8.

6. Hert MD, Schreurs V, Sweers K, Eyck DV, Hanssens $\mathrm{L}$, Sinko $\mathrm{S}$, et al. Typical and atypical antipsychotics differentially affect long-term incidence rates of the metabolic syndrome in first-episode patients with schizophrenia: A retrospective chart review. Schizophr Res. 2008;101:295-303.

7. Lindenmayer JP, Czobor P, Volavka J, Citrome L, Sheitman B, McEvoy JP, et al. Changes in glucose and cholesterol levels in patients with schizophrenia treated with typical or atypical antipsychotics. Am J Psychiatry. 2003; 160:290-6.

8. Cohn T, Prud'homme D, Streiner D, Kameh H, Remington G. Characterizing coronary heart disease risk in chronic schizophrenia: High prevalence of the metabolic syndrome. Can J Psychiatry. 2004;49:753-60.

9. McEvoy JP, Meyer JM, Goff DC, Nasrallah HA, Davis SM, Sullivan L, et al. Prevalence of the metabolic syndrome in patients with schizophrenia: Baseline results from the Clinical Antipsychotic Trials of Intervention Effectiveness (CATIE) schizophrenia trial and comparison with national estimates from NHANES III. Schizophr Res. 2005;80:19-32.

10. Hert MD, Winkel RV, Eyck DV, Hanssens L, Wampers M, Scheen A, et al. Prevalence of the metabolic syndrome in patients with schizophrenia treated with antipsychotic medication. Schizophr Res. 2006;83:87-93.

11. Gautam S, Meena PS. Drug-emergent metabolic syndrome in patients with schizophrenia receiving atypical (second-generation) antipsychotics. Indian $\mathbf{J}$ Psychiatry. 2011;53:128-33.

12. Perez-Iglesias R, Crespo-Facorro B, Martinez-Garcia O, Ramirez-Bonilla ML, Alvarez-Jimenez M, Pelayo-Teran JM, et al. Weight gain induced by haloperidol, risperidone and olanzapine after 1 year: Findings of a randomized clinical trial in a drug naïve population. Schizophr Res. 2008;99:13-22.

13. Saddichha S, Manjunatha N, Ameen S, Akhtar S. Metabolic syndrome in first episode schizophrenia-a randomized double-blind controlled, short-term prospective study. Schizophr Res. 2008;101:266-72.

14. Saddichha S, Manjunatha N, Ameen S, Akhtar S. Diabetes and schizophrenia - effect of disease or drug? Results from a randomized,double-blind, controlled prospective study in first-episode schizophrenia. Acta Psychiatr Scand. 2008;117:342-7.

15. Barnwal A, Oza B, Patel V. Metabolic side effects of antipsychotic agents: a prospective study in a teaching hospital. NHL J Med Sci. 2012;1(1):23-6.

16. Grover S, Aggarwal M, Dutt A, Chakrabarti S, Avasthi A, Kulhara P, et al. Prevalence of metabolic 
syndrome in patients with schizophrenia in India. Psychiatry Res. 2012;200:1035-7.

17. Chadda RK, Ramshankar P, Deb KS, Sood M. Metabolic syndrome in schizophrenia: Differences between antipsychotic-naïve and treated patients. J Pharmacol Pharmacother. 2013;4(3):176-86.
Cite this article as Sivagourounadin K, Subbiah V, Krishnasamy G, Rajendran P. A study on haloperidol and risperidone induced metabolic derangements in patients with newly diagnosed schizophrenia. Int $\mathbf{J}$ Basic Clin Pharmacol 2020;9:282-8. 